\title{
Continuous Flow Z-stereoselective Olefin Metathesis: Development and Applications in the Synthesis of Pheromones and Macrocyclic Odorant Molecules
}

\author{
Jennifer Morvan, ${ }^{[a]}$ Tom McBride, ${ }^{[b]}$ Idriss Curbet, ${ }^{[a]}$ Sophie Colombel-Rouen, ${ }^{[a]}$ Thierry Roisnel, ${ }^{[a]}$ Christophe \\ Crévisy, ${ }^{[a]}$ Duncan L. Browne*[c] and Marc Mauduit*[a]
}

\author{
[a] J. Morvan, Dr. I. Curbet, Dr. S. Colombel-Rouen, Dr. T. Roisnel, Dr. C. Crévisy, Dr. M. Mauduit \\ Univ Rennes, Ecole Nationale Supérieure de Chimie de Rennes, CNRS, ISCR UMR 6226, F-35000 Rennes, France \\ E-mail: marc.mauduit@ensc-rennes.fr \\ [b] T. McBride \\ Cardiff Catalysis Institute, School of Chemistry, Cardiff University, Main Building, Park Place, Cardiff, CF10 3AT, UK \\ [c] Dr. D. L. Browne \\ UCL School of Pharmacy (Room 210), 29-39 Brunswick Square, London, WC1 1AX, UK \\ E-mail: duncan.browne@ucl.ac.uk
}

Supporting information for this article is given via a link at the end of the document

Abstract: The first continuous flow Z-selective olefin metathesis process is reported. Key to realizing this process was the adequate choice of stereoselective catalysts combined with the design of an appropriate continuous reactor setup. The designed continuous process permits various self-, cross- and macro-ring-closing- metathesis reactions, delivering products in high selectivity and short residence times. This technique is exemplified by direct application to the preparation of a range of pheromones and macrocyclic odorant molecules and culminates in a telescoped Z-selective cross-metathesis/Dieckmann cyclisation sequence to access (Z)-Civetone, incorporating a serial array of continually stirred tank reactors.

Olefin metathesis ${ }^{1}$ has rapidly emerged as a powerful synthetic tool to construct carbon-carbon double bonds. The versatility of olefin metathesis is evident from its successful application to natural product synthesis, ${ }^{2}$ the valorisation of renewable feedstocks ${ }^{3}$ or the preparation of new materials such as polymers. ${ }^{4}$ The gamut of applications is largely due to the development of efficient, well-defined, air stable and easy to handle catalysts, such as the ruthenium-arylidene complexes which demonstrate high tolerance towards various organic functionalities. ${ }^{1} \mathrm{~A}$ significant challenge for catalyst design has been the selective formation of $Z$-alkenes. As numerous highly valuable molecules feature a $Z$-alkene moiety, special attention has recently been focused on the development of a new class of Ru-based complexes to enable high selectively towards Z-olefins (Figure 1). ${ }^{5}$ Cyclometalated Ru-catalyst Ru1 (Grubbs) ${ }^{6}$ and monothiolate Ru-catalyst Ru-2 (Jensen) ${ }^{7}$ have proved to be highly Z-stereoselective in cross-metathesis (CM) of terminal olefins (up to >99:1) while stereoretentive dithiolate catalyst Ru-3 (Hoveyda) $)^{8}$ efficiently promoted the transformation of $Z$-olefins into corresponding $Z$-products by retaining the stereochemical information (up to >99:1). Recently, we described the synthesis of a cost-effective Z-selective cyclometalated Ru-catalyst $\mathbf{R u}-\mathbf{4}^{9}$ featuring an unsymmetrical unsaturated $\mathrm{NHC}\left(\mathrm{U}_{2}-\mathrm{NHC}\right)$ ligand accessible through a multicomponent process. ${ }^{10} \mathrm{Apart}$ from its high versatility and excellent Z-selectivity demonstrated in self-, cross- and ring-openingpolymerization metathesis, the novel cyclometalated catalyst Ru-4

showed impressive robustness in reactive media affording good fidelity of high Z-selectivity over time, surpassing previously described Rucatalysts. This sought-after feature led us to focus our attention on the development of a continuous flow $Z$-selective process. Over the last decade, continuous flow olefin metathesis has been well studied; with specific emphasis on the Ru-catalysts employed (both hetero- and homogeneous), and a variety of reactor designs, with varying degrees of success..$^{11}$ However, continuous flow $Z$-selective Ru-catalysis has not been reported and remains elusive.

Z-selective or Z-stereoretentive complexes

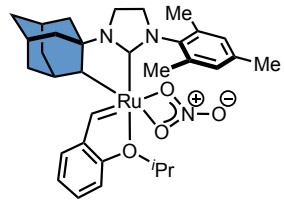

Ru-1 (Grubbs, 2013; Z-selective)

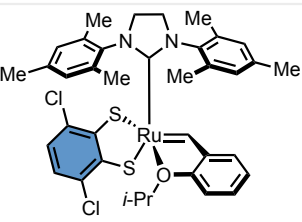

Ru-3 (Hoveyda, 2013; Z-stereoretentive)

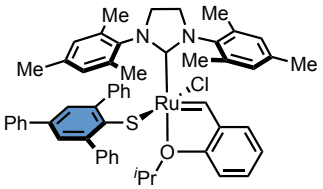

Ru-2 (Jensen, 2013; Z-selective)

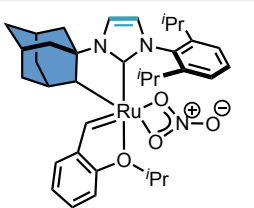

Ru-4 (Mauduit \& Baslé, 2018; Z-selective)

continuous flow Z-stereoselective olefin metathesis (this work)

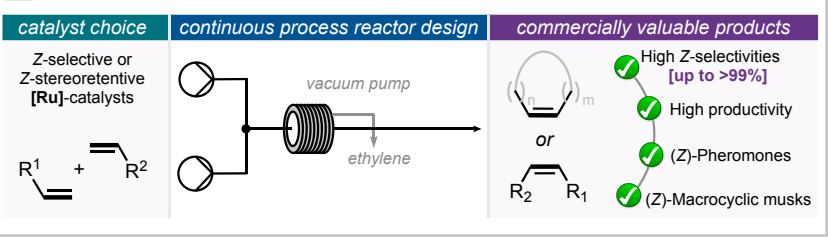

Figure $\mathbf{1}$ a) Previously described Z-stereoselective catalysts (Ru-1,-2 and -4) and stereoretentive catalysts (Ru-3). b) Z-stereoselective continuous flow olefin metathesis (this work). 
In order to realise an effective continuous process, careful attention must be given to both the catalyst choice and the continuous reactor design (Figure 1,b) - but success in this area paths the way to the continuous preparation of a variety of pheromone and odorant molecules. Herein, we describe the first continuous flow Zstereoselective olefin metathesis involving a Teflon AF-2400 tube-intube reactor. ${ }^{12}$

We initiated our study by investigating the application of a Teflon AF2400 tube-in-tube semi-permeable membrane reactor to the Zselective process. Preliminary results highlighted that application of a 'vacuum-on' across the membrane, versus 'vacuum-off' delivered a clear benefit in terms of yield/productivity (See Supplementary Information (SI) for further details). Taking this further, the selfmetathesis of ethyl 9-decenoate under continuous flow condition using a $1 \mathrm{~mL}$ Teflon AF-2400 tube-in-tube reactor ${ }^{12}$ was explored in more detail against a focused collection of catalysts Ru-1, Ru-4 and Ru-5 (Scheme 1. For the gram-scale synthesis of Ru-4,-5 and X-ray characterisation of Ru-5, see SI, Scheme S1 and Figure S4). In the event despite an excellent 95/5 Z/E ratio observed with Ru-1 within $0.5 \mathrm{~h}$, the selectivity dropped gradually as the conversion increased reaching $78 \%$ after $3 \mathrm{~h}$ of reaction (Scheme 2,a). Curiously, the novel Ru-5 catalyst showed a lower range of $Z$-selectivity over time ( 87 to $69 \%$ ) than its parent Ru-1 although the resulting diester $\mathbf{6}$ was produced in a higher yield (84\%, Scheme 2,b). ${ }^{13,14}$ Interestingly, DIPP-containing cyclometalated Ru-4 demonstrated excellent catalytic performance in the flow reactor affording the desired internal olefin with $78 \%$ conversion and very high $97 \%$ Z-selectivity after 3 hours (Scheme 2,c). It is worth underlining that continuous flow metathesis can be conducted outside a glovebox while batch conditions require an open vessel inside the glovebox to efficiently remove the ethylene and reach high conversions. ${ }^{15}$

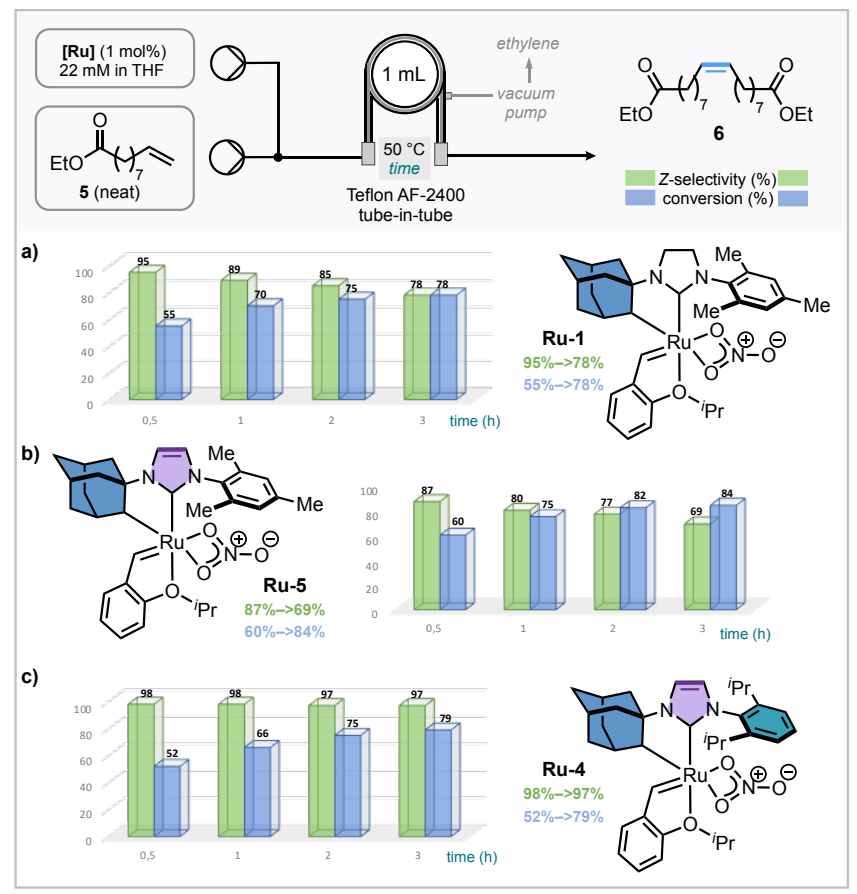

Scheme 1. Catalytic performances of cyclometalated Ru-complexes Ru-1, $-\mathbf{4}$, and $\mathbf{- 5}$ in continuous flow self-metathesis of Ethyl 9-decenoate 5.

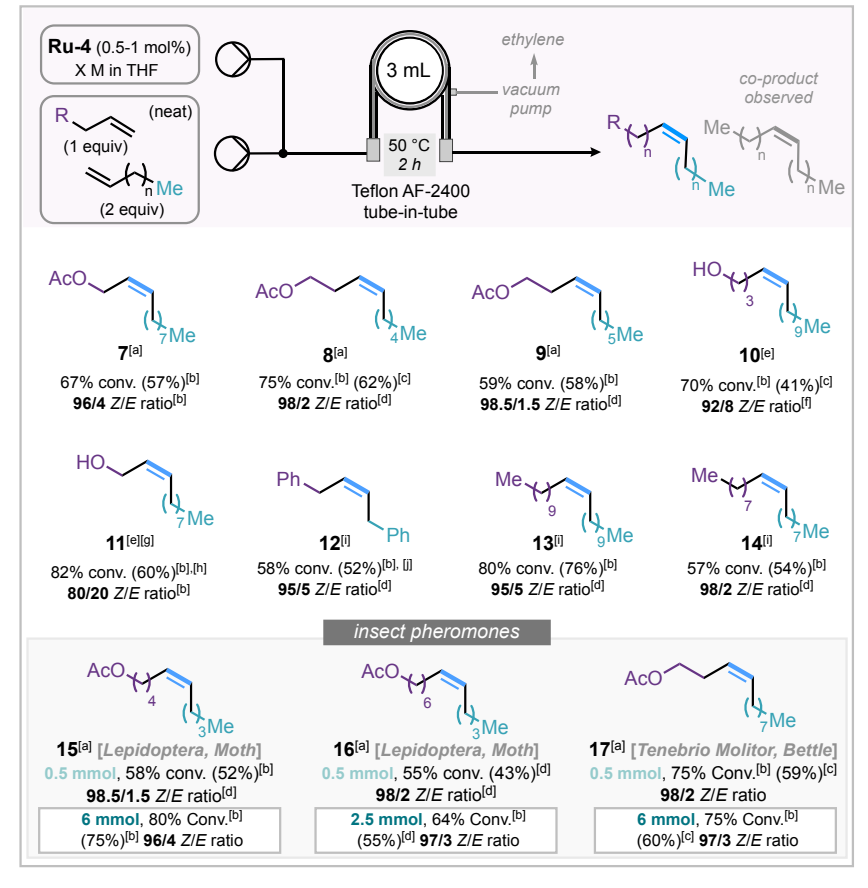

Scheme 2. Scope of continuous flow cross- and self-metathesis catalyzed by Ru-4. [a] Catalyst loading: $1 \mathrm{~mol} \%$ (15-23 mM in THF). [b] Determined by ${ }^{1} \mathrm{H}$ NMR with mesitylene as internal standard. [c] Isolated Yield. [d] Determined by GC. [e] Residence time: $4 \mathrm{~h}$. [f] Determined by quantitative ${ }^{13} \mathrm{C} \mathrm{NMR}$. [g] Catalyst loading: 2 mol\% (40 mM in THF). [h] 13\% of SM-product were detected by ${ }^{1} \mathrm{H}$ NMR. [i] Catalyst loading: $0.5 \mathrm{~mol} \%$ (10-17 mM in THF). [j] 5\% of isomerized by-product from allylbenzene were detected by ${ }^{1} \mathrm{H}$ NMR.

Having identified the combination of $\mathbf{R u - 4}$ and a Teflon AF-2400 vacuum-on tube-in-tube design as the most efficient combination to achieve continuous $Z$-selective catalysis, a range of several cross- and self-metathesis transformations were explored in a larger $3 \mathrm{~mL}$ reactor (Scheme 2). Initially running a range of substrates through the reactor with a two-hour residence time and 1 mol\% catalyst loading led to moderate to good conversions and yields. Notably, all CM products were formed in excellent Z-selectivity, ranging from 94 to $98.5 \%$, with the exception of allylic alcohol 11 which afforded a $Z / E$ ratio of 80/20. Using the designed flow reactor rig, highly valuable semiochemicals 1517, 16 acting as potential bio-pesticides against Lepidoptera (moth) and Tenebrio Molitor (beetle), were efficiently produced on a $6 \mathrm{mmol}$ scale (12 times the standard substrate scope scale) with a slight alteration of Z-selectivity (96-97\%). Furthermore, a 0.5 mol\%, Ru-4 loading was sufficient to promote the self-metathesis of allyl-benzene and other unfunctionalized linear terminal alkenes furnishing, after 2 hours, the corresponding internal Z-olefins 12-14 in excellent selectivity (up to $98 \%$ ) and moderate to good yields.

We next turned our attention to the macro-RCM reaction of terminal olefins. Typically, macro-RCM requires higher dilution than $\mathrm{CM}$ so as to minimise the competitive oligomerization reaction; reaction concentration therefore becomes a variable. ${ }^{14}$ As depicted in Table 1 entries 1 and 2, similar catalytic performances were observed with Ru$\mathbf{1}$ and Ru-5 in the formation of the 16-membered macrocycle $\mathbf{1 9}$ when the reaction was run at $20 \mathrm{mM}^{17}$ in 1,2-dichloroethane $\left(70{ }^{\circ} \mathrm{C}, 3\right.$ hours residence time, $70 \%$ and $75 \%$ isolated yield respectively). Nevertheless, the Z-selectivity still remained moderate reaching $86 \%$ and $82 \%$ respectively. To our delight, $\mathbf{R u}-\mathbf{4}$ showed an impressive $97 / 3 \mathrm{Z} / E$ ratio although a significantly lower productivity was observed $(24 \%$ isolated yield, Table 1, entry 3). By increasing the residence time to $4.5 \mathrm{~h}$ (entry 
4), the yield could be slightly improved without any alteration of $Z$ selectivity demonstrating again the excellent stability of Ru-4. Notably, at a higher concentration $(50 \mathrm{mM})$, similar isolated yield and Zselectivity were observed but a competitive oligomerization occurred (entry 5). Applying these conditions for Ru-4 and Ru-5 (Table 1 entries 2 and 3) in the context of highly desirable macrocyclic odorant molecules, cyclometalated Ru-4 surpassed Ru-5 in the mRCM (at 20 $\mathrm{mM}$ ) providing (Z)-civetone $20,{ }^{18}$ which was isolated in $44 \%$ yield and excellent $95 \%$ Z-selectivity. Surprisingly, Ru-4 was inefficient toward (Z)-yuzu lactone $\mathbf{2 1},{ }^{19}$ where a higher productivity was reached with the parent Ru-5 (32\% isolated yield) but the $Z / E$ ratio remained moderate (82/18).

Table 1. Catalytic performances of cyclometalated Ru-complexes Ru-1,4,5 in continuous flow macro-RCM.
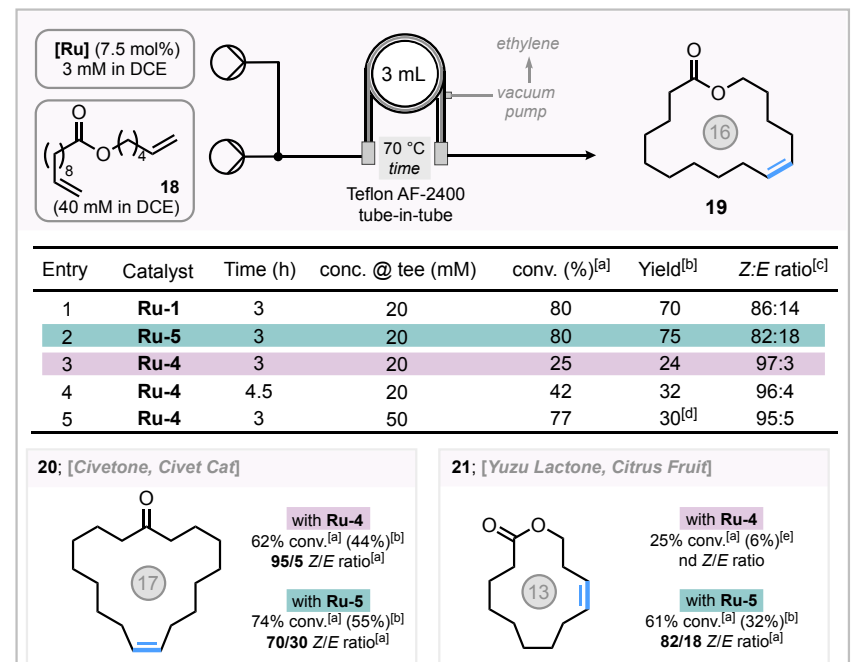

[a] Determined by ${ }^{1} \mathrm{H}$ NMR spectroscopy using mesitylene as internal standard. [b] Isolated yield. [c] Z/E molar ratio were monitored by GC analysis. [d] Oligomers were also detected. [e] ${ }^{1} \mathrm{H}$ NMR yield. $\mathrm{Nd}$ : not determined

Given the deficiencies found in our efforts towards continuous flow Zselective metathesis, namely moderate $Z / E$ ratios observed in $\mathrm{CM}$ involving allylic alcohols (product 11, Scheme 2) and moderate performance in mRCM reactions, we investigated the catalytic performance of the stereoretentive catecholdithiolate catalyst $\mathbf{R u}-\mathbf{3}^{20}$ (Scheme 3). To our delight, the rapid reaction (within $5 \mathrm{~min}$.) between cis-butenediol and 1-undecene led to the desired internal olefin 11 with a remarkable $99 \%$ Z-selectivity and a moderate $56 \%$ yield. It is worth noting that without vacuum, a slightly lower productivity and selectivity were observed despite the limited production of ethylene observed here. Interestingly, the in situ generated Ru-3, which avoids the requirement of a glove-box led to $\mathbf{1 1}$ with the same efficiency (see SI for details). ${ }^{21}$ Furthermore, the stereoretentive Ru-3 catalyst was also able to produce internal olefins 7, 22 and $\mathbf{2 3}$ with moderate to good yields and excellent $Z / E$ ratios (up to $>99 / 1$ ). Unfortunately, Ru-3 was inefficient towards the $\mathrm{mRCM}$ leading to (Z)-yuzu lactone 21 , delivering a low $7 \%$ yield despite a prolonged residence time and higher reaction temperature. As some amounts of dimer by-product were also detected, we suspect that the semi-permeable membrane reactor is unable to efficiently remove the 1-butene co-product.

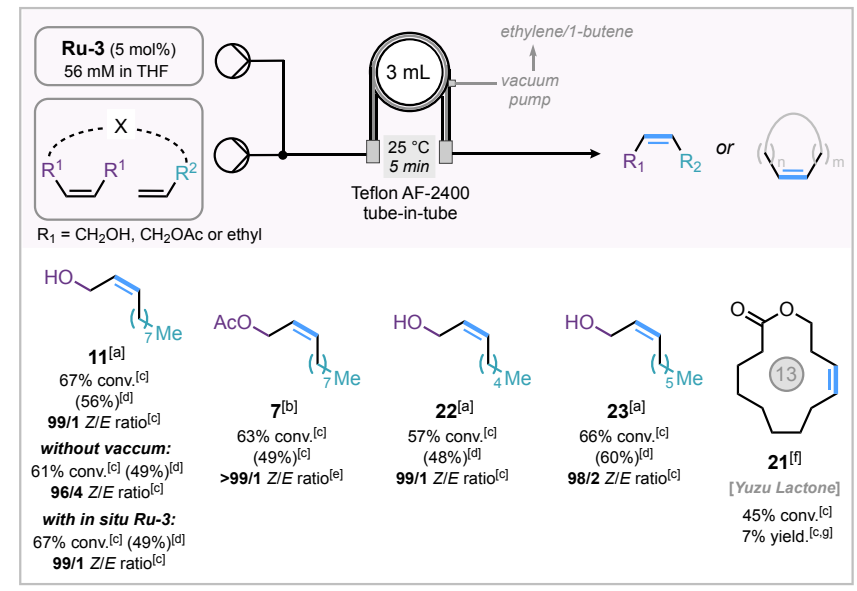

Scheme 3. Catalytic performances of stereoretentive Ru-3 in continuous flow $\mathrm{CM}$ and mRCM. [a] 2 equiv of cis-butenediol were used (1.9 M in THF). [b] 4 equiv of cis-1,3diacetoxy-2-butene were used (neat). [c] Determined by ${ }^{1} \mathrm{H}$ NMR with mesitylene as internal standard. [d] Isolated yield. [e] Determined by GC. [f] Catalyst loading: 6 mol\% (2.4 mM in THF); diene ( $40 \mathrm{mM}$ in THF), $70{ }^{\circ} \mathrm{C}, 3 \mathrm{~h}$. [g] Some amounts of dimer byproduct were also detected.

At last, due to the dilution condition $(20 \mathrm{mM})$ required to produce $Z$ civetone $\mathbf{2 0}$ via macro-RCM (Table1), we envisaged an alternative synthetic route that involves a macrocyclization via a Dieckmann reaction of the Z-diester $6 .{ }^{22}$ Such a proposed route sets a challenge for continuous flow reactor design. Similarly to mRCM, macro-Dieckmann cyclisations also requires careful control over the reactive intermediate concentration, so as to favor cyclisation over oligomerization. Reactions of this type are controlled in batch by dropwise addition of one of the components to keep the concentration of intermediate low, favoring cyclisation (Scheme 4, b). ${ }^{18}$ Design of a reactor to achieve this in flow requires multiple injection points along the length of the reactor, where, at each point a portion of one component is introduced via a mixer to the flowing stream. Depending on the rate of reaction there may need to be a maturing period for the reaction prior to the next 'injection' or 'drop' of material. This can be achieved using a continuous stirred-tank reactor design (CSTR), which can also accommodate active stirring (Scheme 4, c). The use of multiple injection points and CSTRs is also a good reactor design if there is the risk of fouling, bridging or precipitation in the reactor.

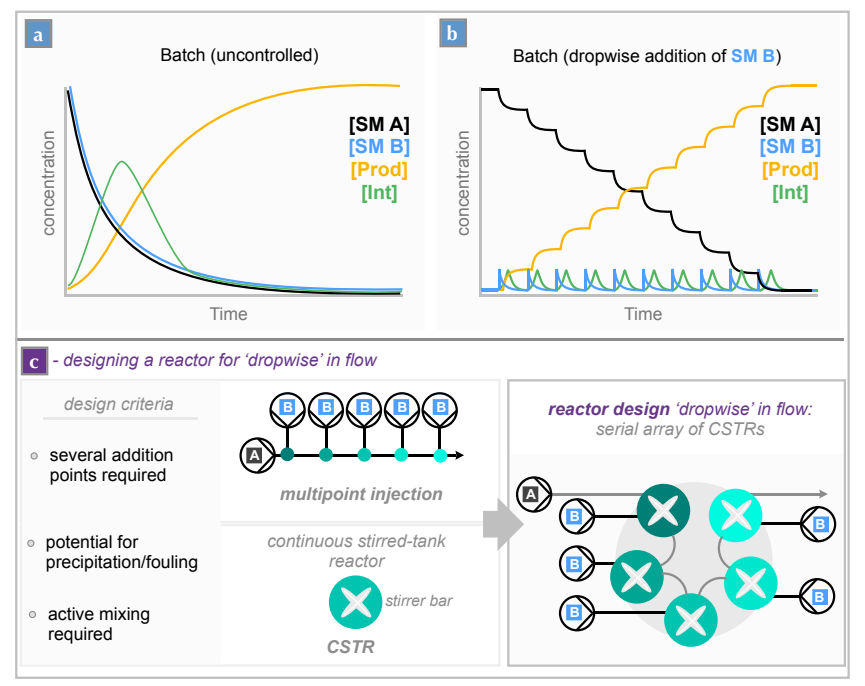

Scheme 4. Reactor design considerations for the continuous macro-Dieckmann cyclisation reaction. 


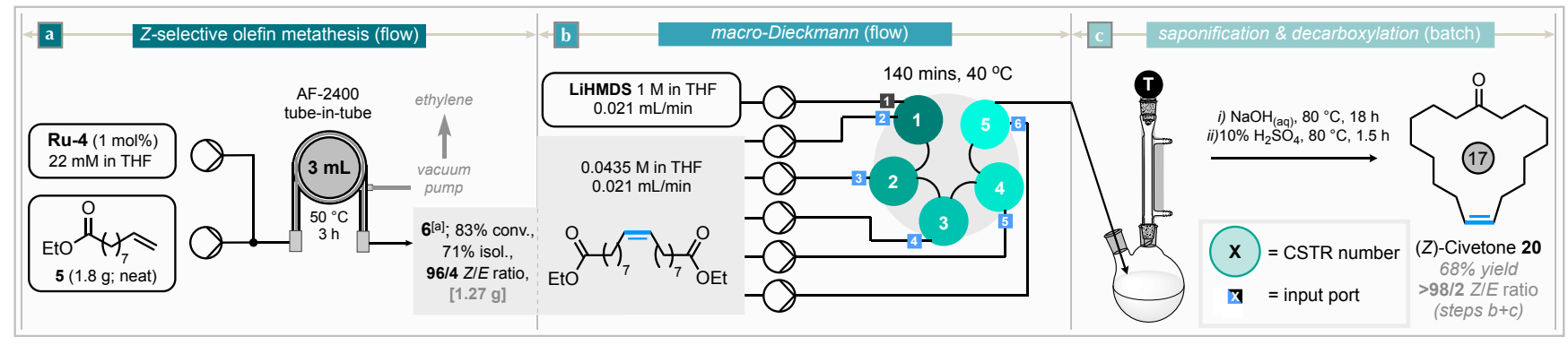

Scheme 5. Reactor design for the telescoped continuous Z-selective cross-metathesis/Dieckmann cyclisation approach to (Z)-Civetone 20.

Deprotonations, or reactions incorporating organometallic reagents can encounter fouling or precipitation issues. Preliminary experimentation with a flow system which simply combined LiHMDS with a full equivalent of diester 6 at a tee-piece, highlighted the propensity to form a precipitate and block the reactor. With this in mind we opted for a reactor design consisting of a serial array of CSTRs. ${ }^{23}$ Incorporating this into a semi-continuous process targeting Civetone, we began with a larger scale self-metathesis of the biosourced ethyl 9-decenoate $\mathbf{5}$ catalyzed by cyclometalated Ru-4. Pleasingly, after 3 hours inside the $3 \mathrm{~mL}$ tube-in-tube reactor, 6 was isolated in good yield $(71 \% ; 1.27 \mathrm{~g}$ ) and excellent $96 \%$ Z-selectivity (Scheme 5, a). Diester 6 was then diluted in THF and split across 5 input feeds. The base, lithium bis(trimethylsilyl)amide (LiHMDS) was used in large excess; such pseudo-first order conditions in base favour macrocyclization. LiHMDS was introduced into the serial CSTR reactor through input port 1 where it met the first portion of diester in tank 1 of the reactor and progressed through the reactor cascade to meet a total of 5 portions of diester before exiting to a batch collection flask (Scheme 5, b). The flowing output was collected into a stirring RBF and a solution of aqueous sodium hydroxide was added and heating commenced to saponify the cyclized ester intermediate (Scheme 5, c). Treatment of the b-keto acid with sulfuric acid induced decarboxylation and furnished (Z)-Civetone in $62 \%$ yield, which is a comparable yield for the batch preparation of this material via a Dieckmann cyclisation approach.

In summary, we have developed the first continuous flow Zstereoselective olefin metathesis. Key to achieving this was finding the right combination of catalyst and reactor design. Among a selection of Z-stereoselective Ru-complexes, cyclometalated Ru-4 as well as dithiolated Ru-3 catalysts have proven to be the most efficient toward the formation of $Z$-internal olefins. Moderate to good yields and remarkable $Z$-selectivity (up to $>99 \%$ ) were obtained in various $\mathrm{CM}$ and $\mathrm{mRCM}$ allowing for the production of highly valuable pheromones and macrocyclic odorant molecules. Additionally, the continuous flow total synthesis of (Z)-Civetone was successfully achieved in $>98 \% \mathrm{Z}$ selectivity and $48 \%$ yield over 3 steps from a biosourced raw material via a Z-selective CM followed by a Dieckmann cyclisation involving serial array of CSTRs.

\section{Acknowledgements}

We are grateful to the CNRS and the Ecole Nationale Supérieure de Chimie de Rennes. This work was supported by the region Bretagne (ARED $2018 \mathrm{~N}^{\circ} 601$ - BIOMETA; grant to JM) and the FASO (grant to IC). TM thanks Cardiff University and EPSRC for a studentship (EP/N509449/1). Umicore AG \& Co is acknowledged for a generous gift of Ru-complexes. We are grateful to Elsa Caytan and the PRISM core facility (Biogenouest $\odot$, UMS, Biosit, Université de Rennes 1) for NMR experiences.

Keywords: Olefin metathesis $\bullet$ Z-selectivity $\bullet$ Continuous Flow • Pheromones $\bullet$ (Z)-Civetone

[1] a) Handbook of Metathesis, 2nd Edition (Eds.: R. H. Grubbs, A. G. Wenzel, D. J. O'Leary, E. Khosravi); Wiley-VCH: Weinheim, Germany, 2015; b) Olefin Metathesis: Theory and Pratice (Ed: K. Grela), John Wiley \& Sons: Hoboken, N. J., 2014; c) O. M. Ogba, N. C. Warner, D. J. O'Leary, R. H. Grubbs, Chem. Soc. Rev. 2018, 47, 4510

[2] Metathesis in Natural Product Synthesis: Strategies, Substrates, and Catalysts (Eds: Cossy, J.; Arseniyadis, S.; Meyer, C.) Wiley-VCH: Weinheim, Germany, 2010.

[3] C. Bruneau, C. Fischmeister in Alkene Metathesis for Transformations of Renewables in Organometallics for Green Catalysis (Eds: P. Dixneuf, J. F. Soulé) Topics in Organometallic Chemistry, vol 63. Springer, 2018.

[4] a) C. Slugovc in Olefin Metathesis: Theory and Practice (Ed: K. Grela) John Wiley \& Sons: Hoboken, N. J., 2014, pp. 329; b) S. Kovacic, C. Slugovc, Mater. Chem. Front., 2020, 4, 2235.

[5] For selected reviews on stereoselective and stereoretentive metathesis, see: a) A. H. Hoveyda, J. Org. Chem. 2014, 79, 4763; b) M. H. Herbert, R. H. Grubbs, Angew. Chem. Int. Ed. 2015, 54, 5018; c) T. P. Montgomery, T. S. Ahmed, R. H. Grubbs, Angew. Chem. Int. Ed. 2017, 56, 11024; d) T. P. Montgomery, A. M. Johns, R. H. Grubbs, Catalysts 2017, 7, 87. e) D. S. Müller, O. Baslé, M. Mauduit, Beilstein J. Org. Chem. 2018, 14, 2999.

[6] a) L. E. Rosenbrugh, M. B. Herbert, V. M. Marx, B. K. Keitz, R. H. Grubbs, J. Am. Chem. Soc. 2013, 135, 1276; For recent developments, see: b) Y. Xu, J. J. Wong, A. E. Samkian, J. Hoon Ko, S. Chen, K. N. Houk, R. H. Grubbs, J. Am. Chem. Soc. 2020, 142, 20987.

[7] a) G. Occhipinti, F. R. Hansen, K. W. Törnroos, V. R. Jensen, J. Am. Chem. Soc. 2013, 135, 3331; For recent developments, see: b) W. Smit, J. B. Ekeli, G. Occhipinti, B. Woźniak, K. W. Törnroos, V. R. Jensen, Organometallics 2020 39, 397.

[8] a) R. K. M. Khan, S. Torker, A. H. Hoveyda, J. Am. Chem. Soc. 2013, 135, 10258; For recent developments, see: b) Z. Liu, C. Xu, J. del Pozo, S. Torker, A. H. Hoveyda, J. Am. Chem. Soc. 2019, 141, 7137.

[9] A. Dumas, R. Tarrieu, T. Vives, T. Roisnel, V. Dorcet, O. Baslé, M. Mauduit, ACS Catal. 2018, 8, 3257.

[10] a) P. Queval, C. Jahier, M. Rouen, I. Artur, J.-C. Legeay, L. Falivene, L. Toupet, C. Crévisy, L. Cavallo, O. Baslé, M. Mauduit, Angew. Chem. Int. Ed. 2013, 52, 14103; b) R. Tarrieu, A. Dumas, J. Thongpaen, T. Vives, T. Roisnel, V. Dorcet, C. Crévisy, O. Baslé, M. Mauduit, J. Org. Chem. 2017, 82, 1880.

[11] (a) A. Michrowska, K. Mennecke, U. Kunz, A. Kirschning, K. Grela, J. Am. Chem. Soc., 2006, 128, 13261; (b) S. Monfette, M. Eyholzer, D. M. Roberge, D. E. Fogg, Chem. Eur. J. 2010, 16, 11720; (c) E. Riva, A. Rencurosi, S. Gagliardi, D. Passarella, M. Martinelli, Chem. Eur. J., 2011, 17, 6221; (d) R. Duque, E. Ochsner, H. Clavier, F. Caijo, S. P. Nolan, M. Mauduit, D. J. Cole-Hamilton, Green Chem., 2011, 13, 1187; (e) E. Borré, M. Rouen, I. Laurent, M. Magrez, F. Caijo, C. Crévisy, W. Solodenko, L. Toupet, R. Frankfurter, C. Vogt, A. Kirschning, M. Mauduit, Chem. Eur. J., 2012, 18, 16369; (f) K. Skowerski, C. Wierzbicka, K. Grela, Curr. Org. Chem., 2013, 17, 2740; (g) W. Solodenko, A. Doppiu, R. Frankfurter, C. Vogt, A. Kirschning, Aust. J. Chem., 2013, 66, 183; (h) R. Munirathinam, J. Huskens, W. Verboom, Adv. Synth. Catal., 2015, 357, 1093; (i) 
M. Bru, R. Dehn, J. H. Teles, S. Deuerlein, M. Danz, I. B. Müller, M. Limbach, Chem. Eur. J., 2013, 19, 11661; (j) E. J. O'Neal, K. F. Jensen, ChemCatChem, 2014, 6, 3004; (k) K. Skowerski, S. J. Czarnocki, P. Knapkiewicz, ChemSusChem, 2014, 7, 536; (I) C. Schotten, D. Plaza, S. Manzini, S. P. Nolan, S. V. Ley, D. L. Browne, A. Lapkin, ACS Sustainable Chem. Eng., 2015, 3, 1453; (m) M. Drop, X. Bantreil, K. Grychowska, G. U. Mahoro, E. Colacino, M. Pawłowski, J. Martinez, G. Subra, P. Zajdel, F. Lamaty, Green Chem. 2017, 19, 1647; (n) É. Morin, J. Sosoe, M. Raymond, B. Amorelli, R. M. Boden, S. K. Collins, Org. Process Res. Dev. 2019, 23, 283.

[12] For previous developments with tube-in-tube reactors, see for instance: a) $M$ O'Brien, I. R. Baxendale, S. V. Ley, Org. Lett. 2010, 12, 1596; b) S. L. Bourne, P. Koos, M. O'Brien, B. Martin, B. Schenkel, I. R. Baxendale, S. V. Ley, Synlett 2011, 18, 2643; c) M. A. Mercadante, N. E. Leadbeater, Org. Biomol. Chem. 2011, 9 , 6575 ; d) S. Kasinathan, S. L. Bourne, P. Tolstoy, P. Koos, M. O'Brien, R. W. Bates, I. R. Baxendale, S. V. Ley, Synlett 2011, 18, 2648; e) A. Polyzos, M. O'Brien, T. P. Petersen, I. R. Baxendale, S. V. Ley, Angew. Chem. Int. Ed. 2011, 50, 1190; f) T. P. Petersen, A. Polyzos, M. O'Brien, T. Ulven, I. R. Baxendale, S. V. Ley, ChemSusChem 2012, 5, 274; g) P. B. Cranwell, M. O'Brien, D. L. Browne, P. Koos, A. Polyzos, M. Pena-Lopez, S. V. Ley, Org. Biomol. Chem. 2012, 10, 5774. For prior use of Teflon AF2400 in tube-in-tube reactors, see for instance: h) I. Pinnau, L. G. Toy, J. Membr. Sci. 1996,109, 125; i) A. Y. Alentiev, V. P. Shantarovich, T. C. Merkel, V. I. Bondar, B. D. Freeman, Y. P. Yampolskii, Macromolecules 2002, 35, 9513; j) T. C. Merkel, V. Bondar, K. Nagai, B. D. Freeman, Y. P. Yampolskii, Macromolecules 1999, 32, 8427; k) S. L. Bourne, M. O'Brien, S. Kasinathan, P. Koos, P. Tolstoy, D. X. Hu, R. W. Bates, B. Martin, B. Schenkel, S. V. Ley, ChemCatChem 2013, 5, 159. I) M. Brzozowski, M. O’Brien, S. V. Ley, A. Polyzos, Acc. Chem. Res. 2015, 48, 349; m) P. B. Cranwell, M. O’Brien, D. L. Browne, P. Koos, A. Polyzos, M. Peña-Lopez, S. V. Ley, Org. Biomol. Chem. 2012, 10, 5774; n) D. L. Browne, M. O'Brien, P. Koos, P. B. Cranwell, A. Polyzos, S. V. Ley, Synlett, 2012, 23, 1402; o) J. C. Pastre, D. L. Browne, M. O'Brien, S. V. Ley, Org. Process Dev. Chem. 2013, 17, 1183; p) F. Mastronardi, B. Gutmann, C. O. Kappe, Org. Lett. 2013, 15, 5590; q) L. Kupracz, A. Kirschning, Adv. Synth. Catal. 2013, 355, 3375.

[13] Those catalytic behaviours were in full accordance with results observed in selfmetathesis reactions conducted in batch conditions (see supplementary information, table S1).

[14] We suspected a premature catalyst decomposition over the time. For decomposition pathways for Z-selective, see: M. B. Herbert, Y. Lan, B. K. Keitz, P. Liu, K. Endo, M. W. Day, K. N. Houk, R. H. Grubbs, J. Am. Chem. Soc. 2012, $134,7861$.

[15] For a recent review on the ethylene effect on efficiency and stereocontrol, see: A. H. Hoveyda, Z. Liu, C. Qin, T. Koengeter, Y. Mu, Angew. Chem. Int. Ed. 2020, 59, 22324.

[16] For an interesting review dealing with the synthesis of semiochemicals via olefin metathesis, see: G. Turczel, E. Kovacs, G. Merza, P. Coish, P. T. Anastas, R. Tuba, ACS Sustainable Chem. Eng. 2019, 7, 33.

[17] Skowerski and co-workers reported the non Z-selective continuous flow synthesis of macrocyclic 8 at higher dilution $(5 \mathrm{mM})$, see ref. $11 \mathrm{k}$

[18] For previous stereoselective synthesis of (Z)-Civetone, see: a) A. Fürstner, G. Seidel, J. Organomet. Chem. 2002, 606, 75; b) Y. Tanabe, A. Makita, S Funakoshi, R. Hamasaki, T. Kawakusu T. Adv. Synth. Catal. 2002, 344, 507; c) H. Hagiwara, T. Adachi, T. Nakamura, T. Hoshi, T. Suzuki, Natural Product Communications, 2012, 7, 913.

[19] a) R. P. Doss, S. J. Gould, K. J. R. Johnson, R. A. Flath, R. L. Kohnert, Phytochemistry 1989, 28, 3311; b) L. Rodefeld, W. Tochtermann, Tetrahedron 1998, 54, 5893.

[20] We used a home-made Ru-3 following a modified procedure, see SI

[21] The in situ formation of dithiolated catalysts is advantageous as it avoids the use of a glove-box for weighing the air-sensitive catalyst Ru-3, see : D. S. Müller, I. Curbet, Y. Raoul, J. Le Nôtre, O. Baslé, M. Mauduit Org. Lett. 2018, 20, 6822.

[22] For a previous stereoselective synthesis of (Z)-Civetone using a Dieckmann condensation, see ref. $18 \mathrm{~b}-\mathrm{c}$.

[23] In this work we have used the fReactor, see: a) M. R. Chapman, M. H. T. Kwan, G. King, K. E. Jolley, M. Hussain, S. Hussain, I. E. Salama, C. G. Niño, L. A. Thompson, M. E. Bayana, A. D. Clayton, B. N. Nguyen, N. J. Turner, N. Kapur, A. J. Blacker, Org. Process Res. Dev. 2017, 21, 1294; b) K. E. Jolley, M. R. Chapman, A. J. Blacker, Beilstein J. Org. Chem. 2018, 14, 2220; c) M. R. Chapman, S. C. Cosgrove, N. J. Turner, N. Kapur, A. J. Blacker, Angew. Chem. Int. Ed. 2018, 57 , 10535. 


\section{Entry for the Table of Contents}

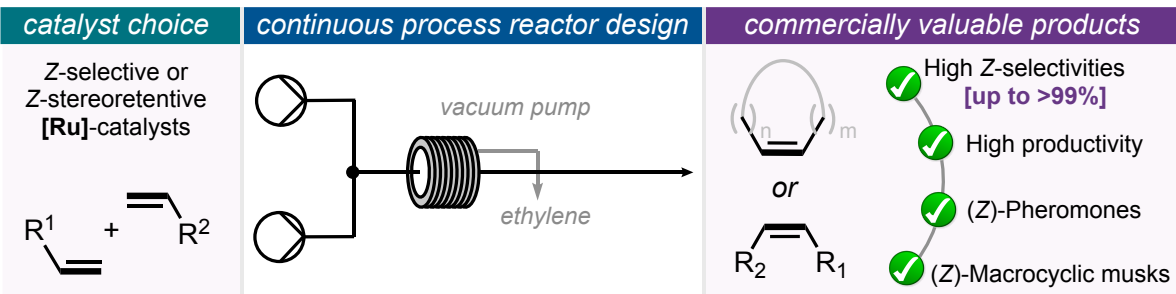

The first continuous flow Z-stereoselective olefin metathesis was described with a set of Z-stereoselective Ru-catalysts. Good productivity and excellent Z-selectivity (up to >99\%) were obtained in the formation of various internal olefins including highly desirable pheromones and macrocyclic odorant molecules. A telescoped Z-selective cross-metathesis/Dieckmann cyclisation sequence to access (Z)-Civetone, incorporating a serial array of continually stirred tank reactors was also reported. 